\title{
La estructuración del espacio urbano y productivo de Gadir durante la Fase Urbana Clásica: cambios y perduraciones
}

\author{
The Structure of Gadir's Urban Area and its Productive Territory During \\ the Urban Classic Period: Changes and Persistence
}

\author{
Ana Ma Niveau de Villedary y Mariñas \\ Universidad de Cádiz ${ }^{1}$ \\ anamaria.niveau@uca.es.
}

Recibido: 13-02-2015

Aceptado: 13-04-2015

\begin{abstract}
RESUMen
La reafirmación del modelo politico-administrativo ciudadano tras la fase arcaica colonial abre una nueva etapa de prosperidad en la antigua fundación tiria. El esplendor de Gadir en el s. V a.C. se refleja en los textos clásicos y en los hallazgos arqueológicos y, sin embargo, nuestros conocimientos sobre el desarrollo histórico de la ciudad de época púnica son muy limitados. El horizonte arcaico comienza a esclarecerse tras los hallazgos del Teatro Cómico que han sacado a la luz los restos de la fundación tiria y, sin embargo, la ciudad posterior continúa siendo una gran incógnita. ¿A qué lugar se traslada la población una vez que se abandona el asentamiento primitivo? ¿Quiénes son los individuos enterrados en los excepcionales sarcófagos antropoides? ¿Qué relación jerárquica existe entre el asentamiento insular y los situados en tierra firme? ¿Qué papel jugó la industria y comercialización de las salazones? Los interrogantes planteados son múltiples y no hacen más que evidenciar la incapacidad del paradigma tradicional para explicar el desarrollo histórico de la Gadir postcolonial y la necesidad de buscar nuevos modelos interpretativos.
\end{abstract}

Palabras Clave: Gadir, Fase Urbana Clásica, articulación del territorio, asentamiento urbano.

\begin{abstract}
The reaffirmation of the citizen's political-administrative model opened up a new stage of prosperity in this ancient city of far western Spain. The splendour of Gadir in the $5^{\text {th }}$ century B.C. has been revealed in classic texts and archaeological findings. Clearly, our knowledge of the urban morphology and historic development of the Punic city is quite limited. As for the Archaic period, we must rely on information provided by excavations conducted under the city's Teatro Cómico, which have revealed remains from the Tyrian settlement, but the subsequent city remains a great unknown for researchers. Where did the population move to after abandoning the primitive settlement? Who is buried in the exceptional anthropoid sarcophagi? What hierarchical relationship existed between the population living on the islands and that living on the mainland? What was the role of the salted fish industry and its commercialization? Numerous questions arise, suggesting the inefficiency of the traditional paradigm in explaining the historical development of Gadir in postcolonial times as well as the need to find new interpretive models.
\end{abstract}

KeY words: Gadir, Urban Classic Period, Territorial Articulation, Urban Settlement. 


\section{El origen de la ciudad y el modelo polinuclear de ocupación del territorio. El cambio del pa- radigma interpretativo}

La investigación sobre la antigua colonia tiria ha estado condicionada desde la Antigüedad por el relato de Estrabón sobre la fundación de Gadir, que recoge la tradición oral de los propios gaditanos (Álvarez Martí-Aguilar 2014). A la escasez de testimonios escritos hay que sumar el halo de leyenda que envuelve la mayor parte de las informaciones que provienen del limes extremooccidental, una frontera más imaginada que real puesto que las costas atlánticas eran conocidas y frecuentadas desde momentos anteriores.

A ello debió contribuir la fama que gozó durante toda la Antigüedad el Herakleion, el templo dedicado a Melqart y principal santuario de la ciudad desde sus orígenes. Sobre la ubicación de éste en los alrededores de la actual isla de Sancti Petri, en el extremo sur del archipiélago, ha existido cierto consenso histórico, aunque junto a la tradicional ubicación, es decir en el propio islo- te, últimamente han aparecido otras propuestas como que se levantara en tierra firme -en la llamada Punta del Boquerón (Frutos y Muñoz 2004: 17) - o incluso en la zona actualmente hundida entre ésta y la isla (Sáez, Montero y Díaz, 2005: 875).

Por el contrario, el lugar donde los fenicios levantaron el asentamiento primitivo ha sido objeto de múltiples especulaciones, no exentas de controversia. Tanto, que la ausencia de vestigios urbanos inequívocos llevó incluso a plantear la posibilidad de que el núcleo fundacional fenicio no se hallara bajo la actual ciudad de Cádiz sino al otro lado de la bahía, en el yacimiento del Castillo de Doña Blanca (El Puerto de Santa María, Cádiz), situado en tierra firme junto a la antigua desembocadura del río Guadalete (Ruiz Mata 1999).

Sin embargo, el panorama arqueológico de Gadir, al menos para época arcaica, se ha aclarado en los últimos años gracias a una serie de hallazgos. Entre éstos destaca la excavación del solar del antiguo Teatro Cómico, donde los trabajos

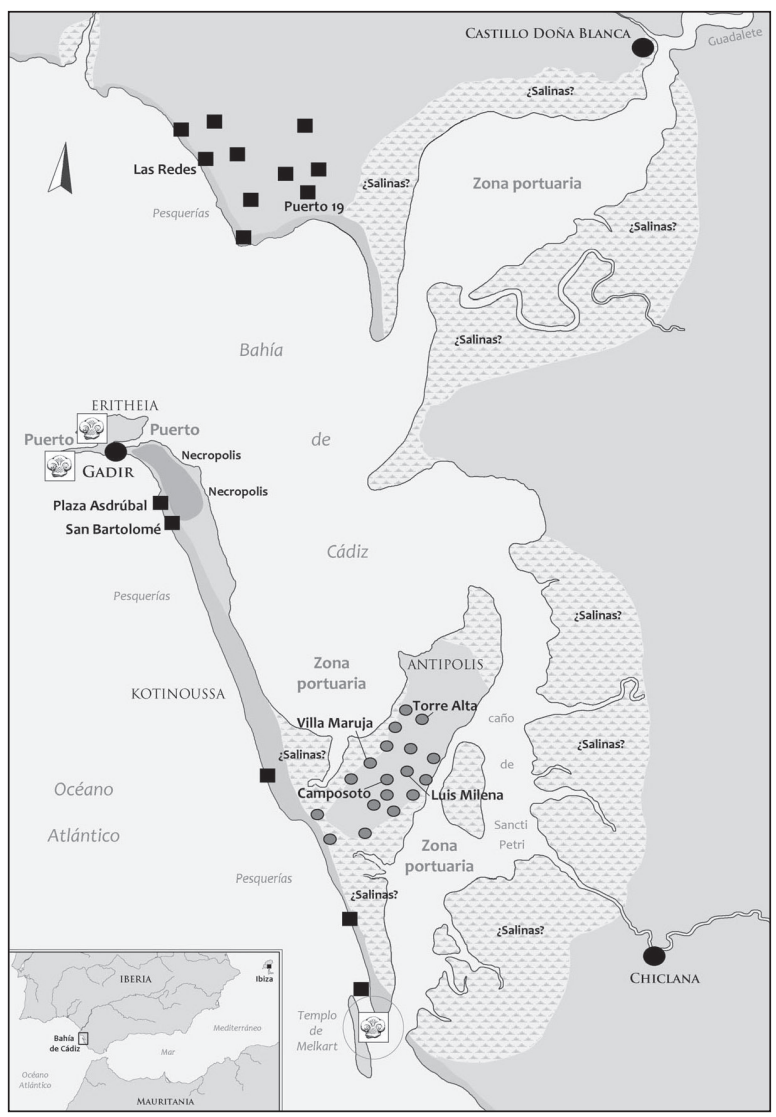

Fig. 1. Bahía de Cádiz y distintas localizaciones citadas en el texto (Sáez 2014: fig. 4). 


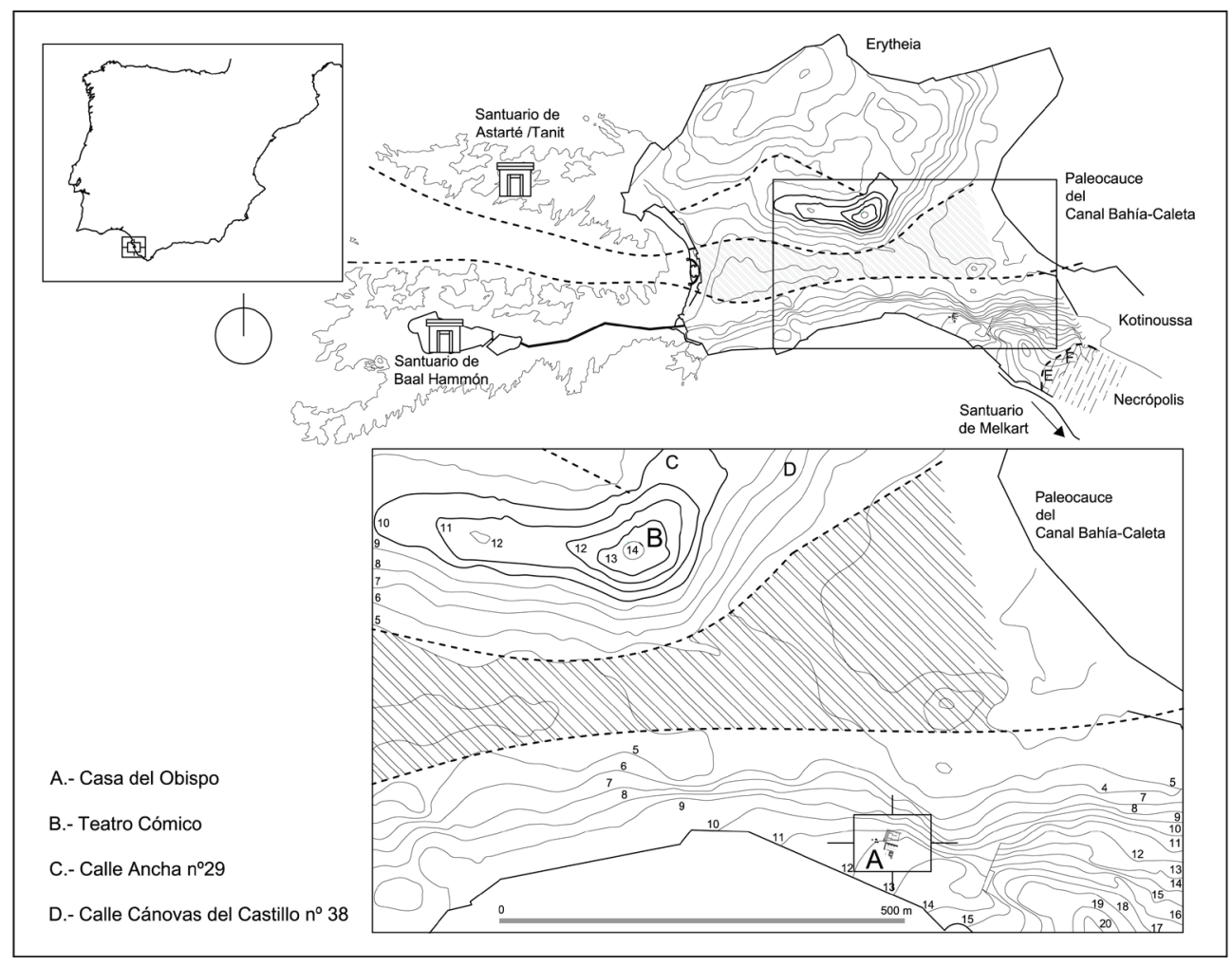

Fig. 2. Plano de la actual ciudad de Cádiz con la localización de los distintos puntos citados en el texto (elaboración: J. M. Gener Basallote).

arqueológicos han sacado a la luz parte del entramado urbano de la ciudad primitiva (Zamora et al. 2010; Gener et al. 2012; Gener et al. 2014a). Todos los datos recabados (el urbanismo, la arquitectura doméstica, el empleo de materiales y técnicas constructivas levantinas, el uso de la escritura, la procedencia de la cultura material, etc.) indican el origen oriental de los restos y sitúan el momento de la fundación hacia finales del s. IX a.C. (Torres et al. 2014: 79), confirmando tanto la ubicación insular del primer asentamiento tirio como la antigüedad del mismo. Secuencialmente, los restos excavados en el Teatro Cómico se insertan en un momento inmediatamente posterior al horizonte "precolonial fenicio" (Torres 2008: 82) o "emporitano-precolonial" (González de Canales, Serrano y Llompart 2006) definido a raíz de los hallazgos de Huelva (González de Canales, Serrano y Llompart 2004) y la Rebanadilla en Málaga (Sánchez et al. 2012). Otros autores, sin embargo, defienden que los restos exhumados en Málaga pertenecen a una colonia sensu stricto, con lo que quedaría definida la existencia de un "horizonte colonial inicial" anterior cronológicamente al "clásico", que es el que se corres- pondería con la fundación gadirita (López Castro 2012: 116-117) que no sería, por tanto, la primera fundación fenicia.

Ahora bien, a pesar de la localización del más que posible asentamiento primitivo bajo el solar de la ciudad de Cádiz, en territorio insular, parece coherente seguir defendiendo, a tenor de los datos materiales y textuales, la existencia de una ciudad polinuclear, con distintos focos localizados en el entorno de la bahía de Cádiz (las Gadei$r a$ de los textos), tanto en las islas como en tierra firme, con funciones diferenciadas (Ruiz Mata 1999; por último, Domínguez Monedero 2012) (Fig. 1).

De acuerdo a este modelo se propone un patrón de asentamiento disgregado con varios núcleos de habitación principales desde época arcaica. El original se localizaría en la parte septentrional del archipiélago gaditano, en la ubicación tradicionalmente propuesta, que queda confirmada tras las últimas excavaciones llevadas a cabo en el casco histórico de la actual ciudad (Teatro Cómico, calle Ancha, Cánovas del Castillo, niveles inferiores del Teatro Andalucía) (Fig. 2). Desde este núcleo principal que no ocuparía una gran 
extensión, el poblamiento debió expandirse desde momentos tempranos hacia tierra firme para facilitar un mejor control territorial, como demuestra el gran recinto urbano amurallado del Castillo de Doña Blanca (Ruiz Mata y Pérez 1995). Algo posterior es el Cerro del Castillo, situado en la parte más alta de la población de Chiclana de la Frontera (Bueno y Cerpa 2008). Este yacimiento posiblemente surgiera en relación con el templo de Melqart junto al que se sitúa, con una funcionalidad similar al Castillo de Doña Blanca.

La actividad industrial presenta también un esquema disociado. Desde el s. VIII a.C. existen vestigios de la realización de actividades pesqueras en el archipiélago (Cobos, Muñoz y Perdigones 1995-96; Córdoba y Ruiz Mata 2005), aunque no hay constancia de la puesta en marcha de una industria conservera con vistas a la comercialización de los productos marinos gaditanos a gran escala hasta los ss. VI-V a.C. (por último, Sáez 2014). Mientras que los saladeros se localizan preferentemente en la costa interior de la bahía y en la cara insular abierta al océano, los alfares que fabrican los envases para la comercialización de los productos se ubican en la actual población de San Fernando, identificada tradicionalmente con Antípolis, la tercera isla citada por los autores clásicos. El territorio dispone de condiciones geológicas y naturales inmejorables para el desarrollo de la industria alfarera, excelentes arcillas y recursos hídricos abundantes en un paisaje marismeño interconectado mediante caños navegables que comunican el interior de la bahía de Cádiz (y, por tanto, las factorías de salazones) con el océano abierto y que constituye una de las salidas naturales de las mercancías.

Tanto la producción como el tráfico comercial pudieron estar gestionados por el vecino templo de Melqart, centro religioso, ideológico y económico además de hito geográfico, que marca la frontera territorial meridional de Gadir como entidad política, de acuerdo con la interpretación defendida por Ruiz Mata (1999: 291).

En el límite septentrional -en la isla menor, Erytheia - se emplaza el santuario de Astarté, identificado gracias a las ofrendas votivas localizadas en el entorno y que pervivirá en época romana bajo la advocación de Venus Marina. Frente a él, en el extremo norte de la isla de $\mathrm{Ko}$ tinoussa, en el promontorio de San Sebastián junto al faro moderno, la tradición historiográfica ha venido situando el Kronion o templo dedicado a Baal-Hammon que cita Estrabón, sin más pruebas materiales que ciertos indicios indirectos como la aparición de restos de basamentos monumentales (Maya et al. 2014: 160-162) y la supuesta localización del capitel protoeólico en las inmediaciones (Marín Ceballos y Jiménez Flores 2011a). Algún autor ha propuesto incluso que se tratase de un espacio "sagrado y conceptualizado" y que "no estuviese representado por un templo sino por un punto topográfico destacado y su importancia residiese en el culto" (Ruiz Mata 1999: 301). No obstante, las recientes intervenciones llevadas a cabo en el sitio han sacado a la luz algunos restos constructivos y materiales fechados entre finales del s. VII y principios del VI a.C. (Maya et al. 2014) que sin duda contribuirán a despejar las dudas sobre la ocupación y funcionalidad del sitio.

Otra de las ubicaciones tradicionales propuesta para el Kronion es el espacio, hacia el sur, donde se sitúa la actual Catedral, cuya funcionalidad ritual/religiosa queda constatada desde época antigua a partir de los hallazgos realizados en la conocida por Casa del Obispo. En esta ubicación se entierra hacia finales del s. VI a.C. un destacado personaje de la comunidad en una tumba monumental alejada del área de necrópolis habitual, seguramente de forma intencionada (Gener, Jurado y Pajuelo e.p.). El sitio se concibe como una especie de herôon y genera a su alrededor una intensa actividad cultual que se prolonga en el tiempo y que termina por fosilizar el uso religioso del suelo hasta la actualidad, sucediéndose la construcción de edificios sagrados en los periodos púnico, romano, musulmán y moderno (Gener et al. 2014b). Se trata de un lugar situado en posición central y elevada que controla visual y simbólicamente todo el espacio ocupado por la ciudad, tanto las posiciones insulares como las terrestres, siendo visible desde todos estos lugares.

Las necrópolis también se disponen en el espacio insular. Desconocemos la morfología y localización del cementerio correspondiente al núcleo urbano primitivo, aunque hallazgos recientes (Saéz y Belizón 2014) parecen indicar que pudo situarse al norte del mismo. Una ubicación que ya había sido planteada por algunos investigadores gracias al descubrimiento de la estatuilla del dios Ptah en 1928 en el solar del Edificio de Telefónica situado en la calle Ancha (Ramírez 1982: 104) en un contexto supuestamente funerario pero que quizás haya que reinterpretar desde parámetros rituales a tenor de los resultados de las excavaciones en el $n^{0} 29$ de la misma calle, donde se exhumó un pozo relleno de restos óseos animales y cerámicas fenicias que se han relacionado con 
la realización de sacrificios y otros rituales (Ruiz Mata, Pérez y Gómez 2014).

En cualquier caso, la ubicación del cementerio arcaico en las proximidades del hábitat no disentiría del patrón de asentamiento fenicio habitual si consideramos que fuera el Arroyo de la Zanja - curso de agua estacional que cruza buena parte del casco antiguo y que desemboca en la Caleta- y no el canal bahía-Caleta, el que separa de forma tanto explícita como simbólica el espacio de los vivos del de los muertos en estos primeros momentos.

La existencia de una necrópolis aristocrática arcaica en Gadir podría inferirse por la presencia de vasos de alabastro egipcios, contenedores empleados como urnas funerarias por la élite fenicia (López Castro 2006). En el caso gaditano el hallazgo de estos recipientes reutilizados en tumbas de época romano imperial y otras estructuras, y nunca en contextos originales, invita a ser cautos respecto a su adscripción automática a enterramientos arcaicos de esta tipología, de los que por ahora no tenemos evidencias directas.

Las estructuras funerarias que se pueden adscribir con seguridad a una necrópolis antigua se fechan en torno a finales del s. VII a.C. principios del s. VI a.C. o (Torres 2010). Se trata de incineraciones in situ en fosa, simples o con canal central, excavadas en grandes fosas en la arcilla natural que se distribuyen por un amplio espacio situado, ahora sí, al sur del núcleo de habitación arcaico, al otro lado del canal bahía-Caleta, el curso de agua que separa Erytheia de Kotinoussa. Sólo de manera excepcional las incineraciones se depositan de forma secundaria en urnas o cistas, localizándose en este caso los ustrina junto a ellas (Alarcón 2010). Con la documentación disponible se puede descartar la existencia de enterramientos en pozos, ya que los ejemplos aducidos responden a una funcionalidad de tipo ritual, bien documentada y estudiada en la misma necrópolis (por último, Niveau de Villedary 2009). Las tumbas de estos momentos se disponen sin un patrón espacial pre-establecido, aunque todas siguen una misma orientación orto-ocaso.

La sustitución del servicio ritual arcaico habitual -formado por un oinochoe de boca de seta $\mathrm{y}$ un jarro trilobulado- por nuevas formas vasculares - platos, ollas, lucernas y cuencos carenados-indica que ya en estos momentos se asiste a un cambio no sólo en las costumbres y creencias funerarias, sino también en la estructura social de estas comunidades. No obstante, la actividad ritual documentada desde la segunda mitad del s.
VIII a.C. en la calle Hércules (en la parte septentrional de Erytheia), con realización de banquetes funerarios en el momento del sepelio en los que debieron participar los deudos en comunión simbólica con el difunto (Sáez y Belizón 2014), tendría continuidad en momentos posteriores, a tenor de la documentación que ofrece la necrópolis del s. VI a.C., ya que en algunos de los busta datados en ese momento se han recuperado materiales orgánicos y fragmentos cerámicos que evidencian la celebración de estos ritos (Perdigones, Muñoz y Pisano 1990: 12; por último, Niveau de Villedary 2006 y 2009).

El enclave arcaico se abandona definitivamente $c a .520$ a.C. (Gener et al. 2014a) y la zona no se vuelve a ocupar hasta finales del s. III a.C., en un momento definido (y mediatizado) por la presencia cartaginesa en la ciudad y que, por tanto, responde a unos condicionantes históricos muy específicos y diferentes. El desembarco de Amílcar Barca en el 237 a.C. provocará un aumento de la población y de la actividad de la ciudad que se refleja en el registro arqueológico en el incremento exponencial de enterramientos (Niveau de Villedary 2009: 190) e instalaciones industriales (Sáez 2014). El aporte de poblaciones foráneas queda asimismo reflejado, como hemos defendido en otras ocasiones, en la constatación de ritos ajenos a la tradición gaditana (Niveau de Villedary 2007: 194).

En definitiva, a la luz de los datos disponibles puede afirmarse que el patrón de asentamiento polinuclear y multifuncional (desde un punto de vista tanto de la apropiación/ocupación del territorio como de la explotación del mismo y de las relaciones sociales que surgen en su seno) descrito para los primeros momentos perdura en el tiempo cristalizando en época púnica, aunque se trata de una realidad dinámica $\mathrm{y}$ en continua transformación que es necesario vertebrar de acuerdo al nuevo marco institucional y sociopolítico.

\section{Abandonos, perduraciones y transforma- ciones de los núcleos de habitación en la tran- sición de la Fase Colonial a la Fase Urbana Plena o Clásica de Gadir}

Si bien el panorama parece que se va clarificando para el periodo colonial, la situación dista mucho de ser clara para los momentos posteriores.

El final del asentamiento primitivo se ha puesto con frecuencia en relación con ciertos acon- 
tecimientos históricos como la destrucción de Tartessos, el asalto al Herakleion gaditano por parte del rey Theron (Macrobio, Sat. I, 20,12; Alvar 1986) o el conflicto bélico de Gadir con las poblaciones vecinas y la posterior ayuda cartaginesa a su ciudad hermana (Justino, XLIV, 5; López Castro 1992); aunque no existe unanimidad en la datación histórica de estos hechos (Álvarez Martí-Aguilar 2006) y ni tan siquiera en la veracidad de las noticias.

El hábitat arcaico situado sobre el altozano del Teatro Cómico, que se extiende por el Noroeste (con muchas probabilidades hacia la Torre Tavira y puede que hasta la calle Ancha hacia el Norte) y baja hacia el paleocauce del Canal bahía-Caleta (hasta Cánovas del Castillo) que separa ambas islas, se abandona definitivamente hacia el tercer cuarto del s. VI a.C. tras una serie de colapsos y sucesivas reconstrucciones, dando lugar a un prolongado hiatus poblacional, pues el solar no se vuelve a ocupar hasta finales del s. III - principios del s. II a.C., ahora con un uso industrial.

Tampoco se han localizado restos constructivos en las inmediaciones, ni materiales descontextualizados que permitan inferir cualquier tipo de actividad en la zona durante esos siglos, de lo que cabe deducir que el hábitat arcaico situado en Erytheia no tiene continuidad, al menos en el mismo emplazamiento.

Esta circunstancia coincide en el tiempo con la disolución de la sociedad de época colonial y la sustitución de las antiguas estructuras por otras, aunque el hecho es que desconocemos tanto las causas del abandono del enclave original como el lugar donde hubo de trasladarse la población (Niveau de Villedary 2014).

La primera opción es que el hábitat se desplazara hacia el Norte, una vez que la necrópolis se reubica en la isla mayor, pero tampoco en esta zona se han hallado restos posteriores a época arcaica. La otra posibilidad es el traslado de la población al otro lado del canal, a la isla de Kotinoussa, donde también se han documentado vestigios de ocupación desde el s. VIII a.C., posiblemente extraurbana, en el actual Barrio de Santa María (Lavado et al. 2000; Álvarez Rojas 1992; Gener et al. 2014b), aunque desde finales del s. VII a.C. está constatado el uso intensivo de la zona como cementerio (Torres 2010; Blanco 2010). En este sentido, la secuencia de ocupación ininterrumpida del yacimiento de la Casa del Obispo, con una importante actividad centrada en los ss. V-III a.C. invita a considerar,

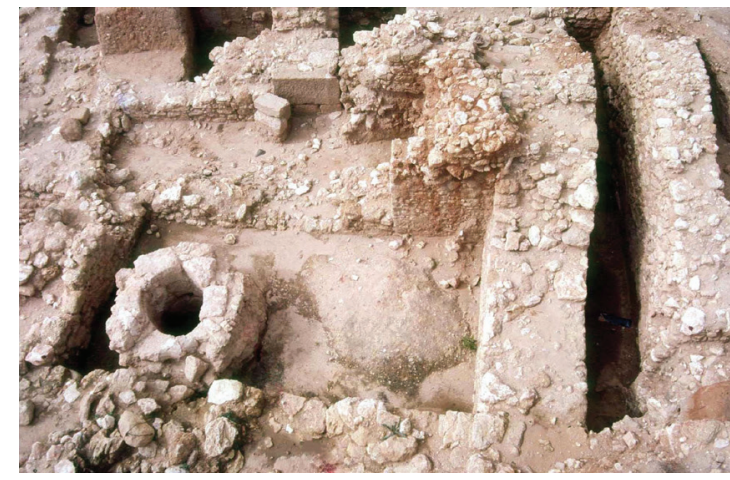

Fig. 3. Castillo de Doña Blanca. Entrada a la ciudad, murallas y pozo de agua (s. V a.C.) (Fotografía: D. Ruiz Mata).

a pesar de la naturaleza ritual de los restos documentados, que la ciudad "nueva" pudiera haberse refundado en su entorno, en los alrededores de la Catedral moderna y bajo la ciudad medieval, en el actual Barrio del Pópulo (Niveau de Villedary 2014).

Los enclaves situados en tierra firme, por su parte, muestran la continuidad del poblamiento, aunque con algunos cambios. El Cerro del Castillo, yacimiento dotado de una muralla de tipo oriental en momentos anteriores, en el s. VI a.C. abandona sus defensas, que se desmantelan, y el espacio es ocupado por estructuras domésticas (Bueno, García-Menárguez y Prados, 2013: 35). También el Castillo de Doña Blanca sufre una remodelación urbanística a finales del s. VI-comienzos del s. V a.C. (Fig. 3) que se hace patente sobre todo en la edificación de una nueva muralla, que aunque sigue el trazado de las defensas arcaicas sobre las que se levanta, se construye con técnicas edilicias novedosas (Ruiz Mata y Pérez 1995: 72). Para su excavador, esta remodelación sería el reflejo de la reactivación económica que sigue a la "crisis" de las estructuras coloniales precedentes, fundamentada en el desarrollo de una potente industria salazonera con vistas a la exportación hacia el Mediterráneo (Ruiz Mata 1988: 45). En cualquier caso, esta industria no hubo de desarrollarse plenamente hasta la segunda mitad de la centuria, si tenemos en cuenta el acusado descenso de cerámicas griegas en el yacimiento durante la primera mitad del s. V a.C., en contraposición con la llegada regular de productos foceos que se constata en momentos anteriores (Cabrera 1998a: 476). 


\section{La eclosión de las células productivas y la articulación del territorio ciudadano en función del binomio saladeros/alfares}

La reactivación del comercio con Grecia se ha explicado tradicionalmente por el establecimiento de relaciones comerciales continuadas entre Gadir y Ampurias, que actuaría de intermediaria de Atenas (Cabrera 1994) o incluso se ha defendido la existencia de un comercio directo AtenasGadir (López Castro 1997). En la actualidad se proponen, sin embargo, vías alternativas, fundamentalmente las mediatizadas por los centros púnicos del Mediterráneo Central: Sicilia, Ibiza y, sobre todo, Cartago, como sucederá más adelante, si nos atenemos al fragmento recogido en los Mirabilia y atribuido al Pseudo Aristóteles (Mirabilia, 136; THA IIB 66g). Aunque el texto se fecha en torno a los ss. IV-III a.C., con más posibilidades en este último, es bastante probable que recogiese noticias más antiguas (García Vargas y Ferrer 2012: 92-94); de hecho, las ánforas del Estrecho aparecen en proporciones destacables en numerosos contextos cartagineses de los ss. V y IV a.C. (Bechtold 2008: 75-77). Entre las importaciones del Castillo de Doña Blanca destacan las ánforas corintias contenedoras de vino y algunos envases áticos de aceite (Cabrera 1998b: 328-329), mientras que el repertorio vascular se compone fundamentalmente de vasos áticos de barniz negro ("copas Cástulo", "copas de la Clase Delicada" y algunas formas tempranas de skyphoi, bolsales y cuencos de una sola asa), faltando los vasos sobrepintados que, no obstante, debieron llegar a Extremo Occidente, como muestra el registro de la Gadir insular (Muñoz 1995-96: 82; Figs. 16 y 17).

En contrapartida, a Grecia y Cartago se exportan las salazones gadiritas (por último, García Vargas y Ferrer 2012), que en estos momentos se comercializan en ánforas de la S11 de Ramon, creación de los talleres gaditanos para envasar los productos pesqueros locales que se convierten, con el tiempo, en la seña de identidad de la producción extremo-occidental, una especie de "marca Gadir".

Coincidiendo con la mención en los textos griegos de los productos gaditanos, el registro muestra la eclosión para estos momentos de un considerable número de núcleos relacionados, de una u otra forma, con la explotación y transformación de los productos pesqueros a lo largo de toda la costa continental e insular (por último, Sáez 2014). Estas instalaciones se interpretaron

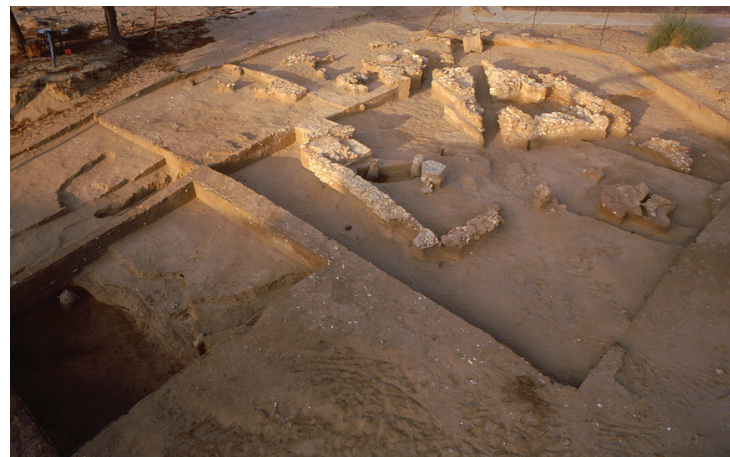

Fig. 4. Vista general de las estructuras exhumadas en Puerto-19 (Sáez 2014: fig. 2).

en un primer momento como células de producción familiares por su reducido tamaño, lo que generó una amplia crítica y el consiguiente debate entre los especialistas (Sáez 2011: 268). En la actualidad, la opinión más generalizada es que se configura una red de establecimientos situados en puntos estratégicos en función de las posibilidades haliéuticas de avistamiento y capturas de los recursos, cuya relación jerárquica o complementaria no queda del todo clara, puesto que la mayor parte de ellos han sido identificados por hallazgos superficiales (en el mejor de los casos mediante la realización de pequeños sondeos) y son pocos los puntos excavados (las factorías portuenses de Las Redes y Puerto-19 situadas en la costa continental y las de Plaza de Asdrúbal y San Bartolomé en la isla de Kotinoussa). Metodológicamente se ha llevado a cabo una distinción funcional entre los enclaves que debieron dedicarse en exclusiva a la pesca y a las primeras actividades de transformación, que no dispondrían de estructuras estables, y aquellos otros en los que tuvieron lugar los procesos de salado y envasado de los productos. Estos últimos se articulan alrededor de construcciones sencillas de planta cuadrada, divididas en distintas dependencias, con presencia de piletas impermeabilizadas y patios descubiertos (Fig. 4); pudiéndose diferenciar distintas zonas de trabajo y vertederos (Sáez, Gutiérrez y Reinoso e.p.). Además de dedicados a la labores de transformación del pescado, debieron funcionar como unidades de habitación de los trabajadores.

Recientemente se ha propuesto que la explotación directa de los recursos a lo largo de las distintas fases del proceso (salinas, pesca, transformación industrial, producción alfarera y envasado de los productos) tuviera lugar mediante concesiones hechas por el templo de Melqart, 


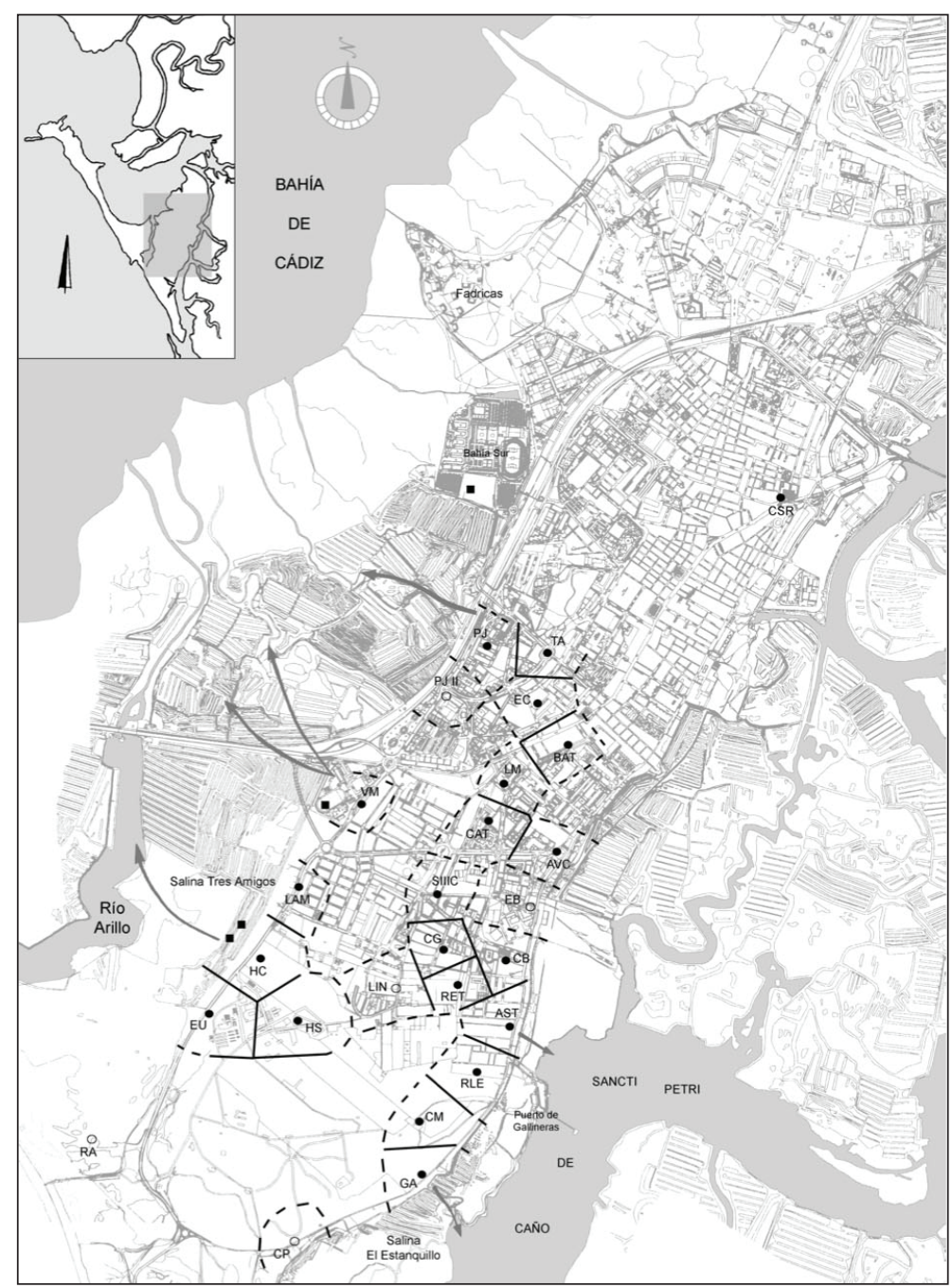

Fig. 5. Propuesta de parcelación de las alfarerías de Antípolis (Sáez 2008: 337; fig. 1).

dueño por tanto de los recursos, a particulares (Sáez 2008: 335). Esto explicaría la parcelación casi geométrica de las áreas de actividad de los talleres alfareros, en los que se incluirían, además de las zonas de trabajo alfarero propiamente dichas, las áreas de captación de recursos (barreros, cursos de agua, embarcaderos, etc.). Este espacio reticulado respondería a una parcelación predeterminada y consciente del territorio productivo, división que prácticamente se mantiene constante en el tiempo (Fig. 5). Para salvar la variable temporal se formula el concepto diacrónico de "área de aprovechamiento alfarero" frente al más estático de "taller", que según Sáez Romero no refleja la continuidad (geográfica pero también tecnológica, organizativa, etc.) de la industria.
Por consiguiente, la antigua isla de San Fernando se revela a partir de época púnica como un territorio intensamente poblado, en principio ocupado casi en exclusiva por instalaciones industriales suburbanas de tipo alfarero (exceptuando el templo de Melqart situado en su extremo más meridional), en el que no se localizan zonas destacadas de habitación más allá de las que hubieron de ocupar los propios trabajadores de los alfares junto a éstos, como parece derivarse de la presencia de enterramientos en las proximidades de muchas de estas instalaciones (Sáez y Díaz 2010). De ahí que se haya propuesto identificar a la Antípolis de las fuentes con el "barrio alfarero de Gadir".

De la situación expuesta se deduce que la transición de la Fase Arcaica al periodo Urbano Pleno o Clásico en Gadir posiblemente debió conllevar 
la ordenación del territorio de la ciudad y su hinterland productivo más inmediato -desde el punto de vista tanto físico como jurídico (Sáez, Gutiérrez y Reinoso e.p.). Este último incluiría, al menos, la costa continental que bordea la bahía además del archipiélago, que pese a todo seguiría manteniendo una funcionalidad primordialmente administrativa, religiosa y simbólica.

\section{El enterramiento monumental de la Casa del Obispo ¿bisagra entre dos épocas?}

Entre los años 1997-2000 se excava la sede del Palacio Episcopal, conocida popularmente por Casa del Obispo y situada entre las dos Catedrales gaditanas, documentándose una secuencia ininterrumpida de ocupación del sitio desde el s. VIII a.C. hasta la actualidad. De acuerdo con sus excavadores, la fase más antigua se corresponde con un nivel de habitación, aunque a partir del s. VI a.C. el lugar adopta un carácter simbólico y sacro que perdura hasta nuestros días.

En esta fecha se construye un enterramiento monumental que inaugura la actividad ritual en el sitio. Gracias a los restos que han llegado a nosotros es posible proponer la existencia, por paralelos con otros lugares púnicos, de un monumento funerario turriforme del tipo conocido como $\mathrm{Ne}$ - fesh (Prados 2008), del que sólo se conservan la cámara funeraria y el basamento, formado por tres cuerpos escalonados; aunque también se ha sugerido la posibilidad de que se trate de una tumba templo o una tumba altar (Gener, Jurado y Pajuelo e.p.). La dignidad del personaje queda atestiguada, en primer lugar, por la elección del sitio donde se entierra, apartada del área de necrópolis y en un lugar elevado desde el que se divisan los principales hitos naturales, religiosos y urbanos de la ciudad, seguidamente por la propia monumentalidad de la construcción y, por último, por el tratamiento que recibió el cadáver (Domínguez-Bella et al. 2011), ungido con aceites y perfumes, ataviado con ricos ropajes de púrpura y oro, enterrado sobre un rico catafalco de maderas exóticas y acompañado por el emblema de su cargo (¿político, religioso?), que debió transmitirse durante al menos tres generaciones (Perea et al. 2004).

La realidad es que la tumba de este personaje, en el que se ha querido ver a uno de los sufetes o a un sumo sacerdote de la ciudad, se convierte de forma inmediata en un lugar de culto y peregrinación, alrededor de la cual se desarrollan rituales y ofrendas durante cerca de tres centurias (ss. V-III a.C.) (Fig. 6). Junto a ella se construyen además una serie de dependencias subterráneas que serán la base sobre las que se levanten los templos de épocas republicana e imperial y que posiblemen-

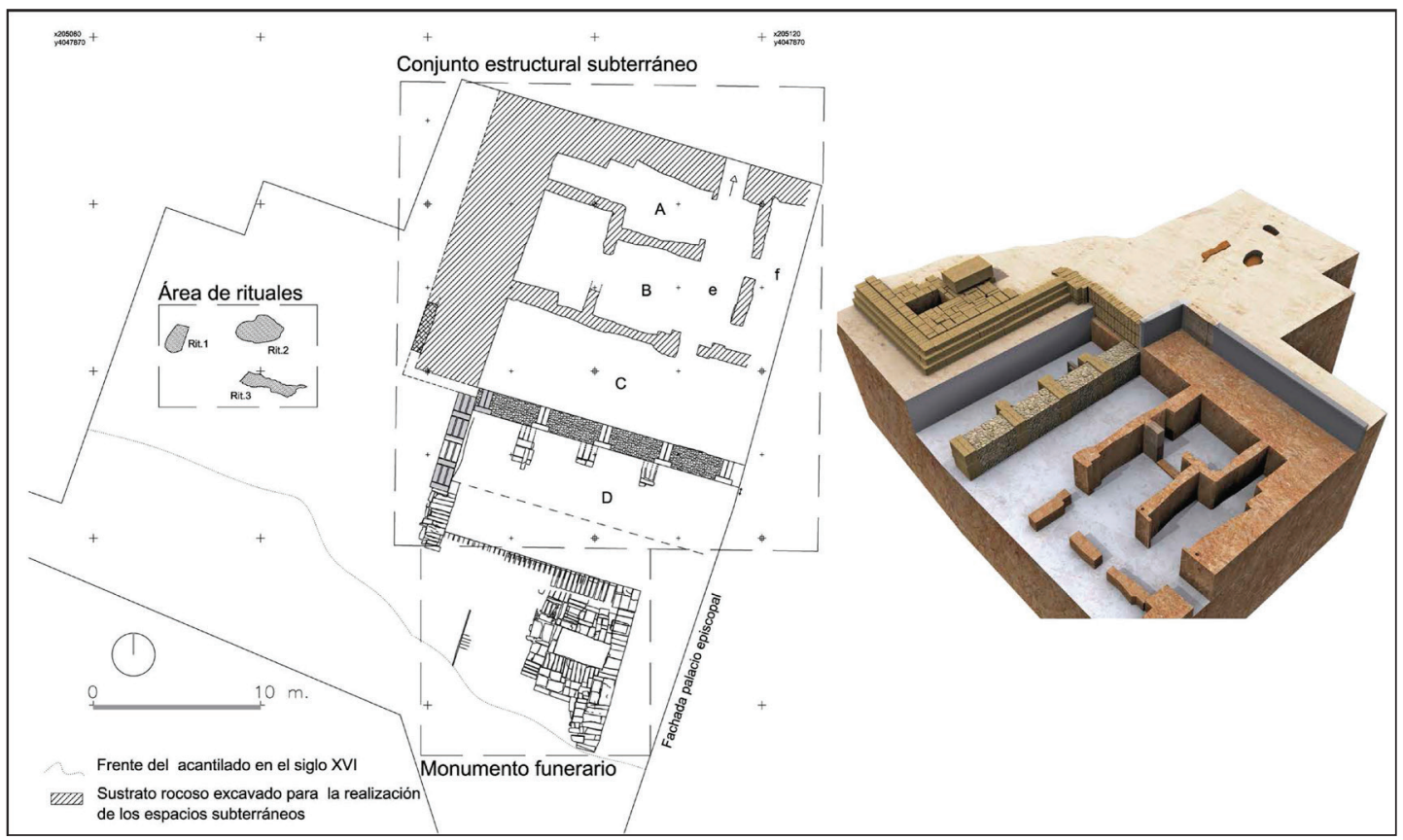

Fig. 6. Planta y reconstrucción del complejo cultual de época púnica de la Casa del Obispo: estancias subterráneas, monumento funerario y área de rituales (Gener et al. 2014b: fig. 3). 
te haya que relacionar con cultos de tipo ctónico. Estos rituales tienen lugar directamente sobre la arena, destacando la quema de perfumes y la realización de pequeños banquetes, con una importante presencia del pescado, que se presenta cocinado en lopas o chytraes (Gener et al. 2014b: 144-145).

Analizado el conjunto en su contexto históricoarqueológico, son varios los aspectos a destacar. En primer lugar, la posición del propio enterramiento, en un lugar apartado de la necrópolis -que ya se ha trasladado a Kotinoussa (Perdigones, Muñoz y Pisano 1990; por último, Torres 2010)-y preeminente desde el punto de vista de la paleogeografía de las islas. El segundo lugar, el rito empleado. En un contexto en el que domina la incineración, se emplea por primera vez la inhumación como preludio del cambio que no tardará en imponerse, ya que las tumbas predominantes hasta el momento (incineraciones primarias o busta en fosas simples excavadas en el terreno) van a ser sustituidas en la siguiente centuria por estructuras de cistas construidas con sillares. Una trasposición al resto de la población de las características principales de esta nueva forma de enterrarse (¿quizás de las élites?) que no tardará en reflejarse en los cementerios.

Estas evidencias, a su vez, nos llevan a plantearnos la naturaleza del personaje enterrado y los méritos que le llevaron a convertirse en un referente para los gadiritas. Resulta muy tentador, analizado el contexto histórico, suponer que tuviera una actuación destacada en la defensa de la ciudad frente a presumibles peligros exteriores -aquellos que terminan con el asentamiento del Teatro Cómico-, incluso que fuera el caudillo que materializó el traslado de la población desde el antiguo núcleo de Erytheia hasta el (supuesto) nuevo emplazamiento situado al norte de Kotinoussa (Niveau de Villedary 2014).

En cualquier caso, de lo que no cabe duda es que resulta el símbolo perfecto que encarna el paso de una época a otra, la paulatina disolución de las viejas estructuras de Época Arcaica y la reafirmación de las nuevas identidades ciudadanas occidentales del que hemos denominado Periodo Clásico Urbano.

\section{Las evidencias funerarias de la Etapa Clásica Urbana. Hacia la definición de una nueva identidad ciudadana}

Aunque desconocemos la ubicación y naturaleza del hábitat post-colonial insular y sólo contamos con datos parciales sobre los núcleos urbanos continentales de esta época, la información procedente de las necrópolis suple en gran medida este vacío. Si bien el cementerio de época arcaica apenas si se adivina, a partir de fines del s. VII a.C. se constata el uso funerario de la isla de Kotinoussa, puesto que la necrópolis se extiende, ahora sí, desde el propio barrio de Santa María, en el extremo norte de la isla, por toda la actual zona de Puerta de Tierra en el istmo (Torres 2010).

La localización en las islas de una necrópolis arcaica es más que probable desde el momento en que queda plenamente constatada la existencia de un grupo poblacional permanente en Erytheia, cuyo alcance real aún hay que valorar, aunque el núcleo original debió ser reducido a tenor de los vestigios disponibles y de los solares excavados en las inmediaciones (Ruiz Mata, Pérez y Gómez 2014: 85).

En este sentido, podría defenderse la existencia de una necrópolis aristocrática segregada de acuerdo al modelo de las halladas en algunas de las colonias de la costa mediterránea andaluza. Desde hace tiempo se ha venido planteando la existencia de un cementerio arcaico, basándose exclusivamente en la existencia de una serie de elementos descontextualizados, muchos de ellos de procedencia dudosa (Muñoz 1998). Tampoco las construcciones halladas en la calle Ancha parecen a priori de naturaleza funeraria. La estructura excavada en el $n^{\circ} 29$ del vial se interpretó en un primer momento como una tumba de pozo, pero tras su análisis material y contextual la función de la misma se ha considerado votiva, siempre valorando su probable relación con la necrópolis, que muy posiblemente se situara en las cercanías (Ruiz Mata, Pérez y Gómez 2014). Tampoco queda clara la naturaleza funeraria de la edificación en la que se halló a comienzos del s. XX la figurilla de Ptah, de la que sólo nos ha llegado la descripción de algunos de los testigos de su hallazgo (y destrucción) (Ramírez Delgado 1982: 102-104). Aunque resulta tentador presuponer que pudiera tratarse de una cámara funeraria como a veces se ha sugerido (Muñoz 1998: 136-138), no existe ningún argumento sólido para sostener tal hipótesis.

A los argumentos esgrimidos tradicionalmente hay que sumar ahora el reciente hallazgo de calle Hércules, que retrotrae las evidencias funerarias al menos a mediados del s. VIII a.C. (Sáez y Belizón 2014), aunque la realidad es que hasta finales del s. VII-comienzos del VI a.C. no se constatan los primeros testimonios inequívocos de la 
existencia de una necrópolis propiamente dicha. Se trata, salvo alguna excepción de cremaciones secundarias depositadas en urnas (Alarcón 2010: 104-106), de incineraciones tipo bustum, simples o con canal central, estas últimas más antiguas. No podemos asegurar a ciencia cierta si la costumbre de utilizar de forma generalizada como pira la misma fosa donde luego se depositan los restos del difunto continúa una tradición anterior, como podría desprenderse de las informaciones más recientes (calle Hércules). En todo caso, nos parece arriesgado, ante un único ejemplo, hacer propuestas generalistas sobre la naturaleza de la necrópolis arcaica de Gadir. Si esta forma de enterramiento convivió en las islas gaditanas en los momentos más antiguos con otras, es un hecho que deberá ser contrastado mediante futuros hallazgos, hoy poco más se puede hacer que proponer de forma hipotética la posible existencia de varias necrópolis.

Sin embargo, si volvemos la vista a la necrópolis continental de Las Cumbres, situada junto al asentamiento del Castillo de Doña Blanca, y la valoramos desde una nueva perspectiva -la que nos ha dado el cambio de paradigma interpretativo del último decenio, sobrevenido a raíz de los hallazgos de Huelva, de los niveles arcaicos de Gadir y del resto de testimonios de cronología temprana y la revisión al alza de la cronología inicial de la colonización en el Extremo Occidente- quizás debamos interpretarla no ya como una necrópolis indígena rápidamente orientalizada (Ruiz Mata y Pérez 1989: 293), sino como un cementerio mixto o híbrido que surge de forma paralela al asentamiento continental para dar morada final a todos sus habitantes. El asunto estaría en determinar si entre los individuos sepultados se puede diferenciar a los orientales sensu stricto de las poblaciones locales, o si podría considerase ya el cementerio de una población fruto de un rápido y temprano proceso de hibridación. Desde esta óptica se podría explicar la conjunción de elementos autóctonos (como la cubierta tumular $\mathrm{y}$ algunos materiales) y orientales (rituales asociados, cultura material, etc.).

Actualmente se acepta que la falta de homogeneidad tipológica y ritual de los enterramientos fenicios no responde a factores geográficos y ni tan siquiera étnicos o culturales, sino a diferencias de tipo social (Aubet 2010: 154-155). Las Cumbres, igual que la necrópolis fenicia de Tiro Al-Bass, no sería sino el cementerio donde se entierran esos segmentos sociales más modestos formado por hombres libres, artesanos y peque- ños comerciantes, que se habrían asentado desde un primer momento en la ciudad situada en tierra firme, en estrecha convivencia con la población local.

En cualquier caso, la realidad es que a partir de finales del VII-principios del VI a.C. comienzan a documentarse tumbas con características muy similares en cuanto a la tipología, el ritual desarrollado y los elementos de ajuar (Torres 2010) que se distribuyen por buena parte de $\mathrm{Ko}$ tinoussa, circunstancia reseñable toda vez que la densidad de ocupación del espacio funerario es relativamente baja aún. Junto a esto, es conveniente recalcar, por una parte, el hecho de que los enterramientos aparezcan en un gran porcentaje formando agrupaciones evidentes y, por otra, la continuidad del espacio funerario en el tiempo, en el que se van superponiendo las distintas necrópolis hasta época tardoantigua.

La isonomía de los enterramientos, la agrupación de los mismos en conjuntos más o menos aislados (¿panteones familiares?) y la baja densidad de ocupación en relación con la amplitud de la totalidad del espacio funerario disponible caracterizarán también a la necrópolis de la siguiente centuria que, sin embargo, rompe con la tradición anterior al imponerse de forma generalizada el rito de la inhumación y el nuevo modelo de tumba de cista construida con sillares de piedra local (Muñoz 1983-84), mal llamadas hipogéicas en la literatura local. En este momento desaparecen por completo los ajuares cerámicos, que a partir de ahora se limitan a alguna pieza de joyería y otros elementos de adorno personal o amuletos.

A nuestro juicio, la lectura de estas evidencias debe ser acometida, al menos, desde una doble perspectiva. En primer lugar en clave espacial, ya que la documentación de una necrópolis de los ss. V-IV a.C., es decir, posterior al abandono del núcleo de habitación arcaico, permite inferir la continuidad del núcleo poblacional insular a pesar de no conocer con certeza el lugar exacto al que se trasladó. Una ciudad que tampoco hubo de tener unas dimensiones mucho mayores que la primera, como se deduce tanto de los testimonios escritos (Estrabón, 3, 5, 3) como de las propias evidencias materiales (Niveau de Villedary 2014). Y, por otra parte, en clave social, puesto que la progresiva multiplicación del número de enterramientos y la homogeneización de los mismos responde, como se ha visto en otros cementerios, a la aparición de necrópolis ciudadanas, en las que los enterramientos aumentan de forma 


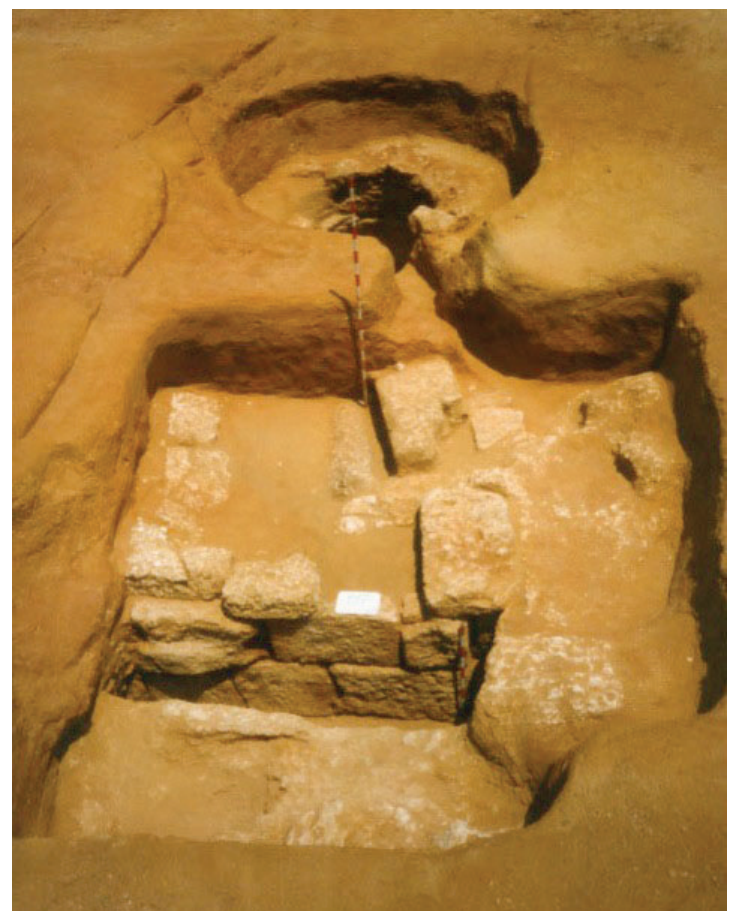

Fig. 7. Conjunto estructural funerario del s. V a.C. -Cuarteles de Varela, 1999- (Fotografía: Francisco J. Blanco).

exponencial cuantitativa -en relación al crecimiento demográfico de la población en términos absolutos- y cualitativamente -en tanto en cuanto que se amplía el número de individuos que adquiere el derecho a enterrarse en ellas (Ferrer 2010: 83)-; un fenómeno que se ha asociado con el proceso de génesis y consolidación de estructuras cívicas-ciudadanas propias en las antiguas colonias fenicias (López Castro 2003: 80), que en relación con Gadir, no obstante, habría que matizar, puesto que no cabe dudar de la naturaleza urbana del asentamiento desde su origen (Padilla 2014: 16).

También los rituales practicados tanto en el momento de la muerte, como durante el cierre de la tumba y la clausura definitiva del espacio funerario, presentan una continuidad que es posible rastrear en el tiempo desde las evidencias arcaicas de calle Hércules y de los enterramientos de los ss. VII-VI a.C. A este respecto destaca un conjunto excavado en la misma fosa funeraria, formado por dos tumbas de cista conectadas a un pozo, en el que se documentaron restos de banquetes, hogueras rituales, ofrendas de animales y libaciones y que por la presencia de ánforas y vasos griegos pudo ser fechado a comienzos del

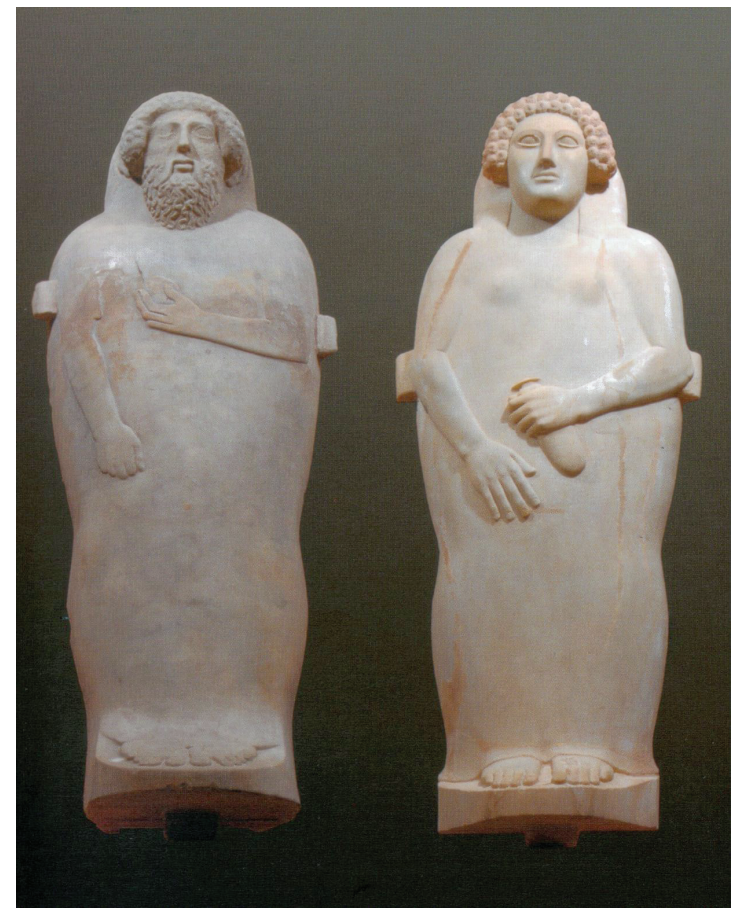

Fig. 8. Sarcófagos antropoides sidonios (Fotografía: Museo de Cádiz).

s. V a.C. (Niveau de Villedary 2009: 188-190) (Fig. 7).

En el paisaje funerario descrito, caracterizado por la presencia de conjuntos estructurales formados por varios enterramientos que se disponen en la misma fosa funeraria, adosados unos a otros y que se han interpretado como panteones familiares, destacan las tumbas que contenían los sarcófagos antropoides sidonios (Fig. 8). En Oriente, de donde son originarios, se trata de féretros destinados en exclusiva a los miembros de la realeza, lo que ha dado pie a hipotetizar sobre la posibilidad de la implantación de una monarquía en Gadir a semejanza de la metropolitana, aunque sin una base sólida.

En los ejemplares hallados en Gadir se debieron enterrar personajes locales destacados, bien herederos directos de la vieja aristocracia tiria o con más probabilidades pertenecientes a la oligarquía ciudadana forjada en Occidente (Almagro-Gorbea et al. 2010: 386-387). Con todo, estos contenedores funerarios no debieron constituir mercancías al uso, sino que posiblemente formaron parte de un comercio o intercambio de dones al más alto nivel (¿entre Estados y/o dignatarios?). Se ha propuesto que fuesen "encargos" concretos hechos a los talleres orientales (irea- 
les?) por parte de determinados individuos que en vida ostentaron altas dignidades civiles $\mathrm{y} / \mathrm{o}$ religiosas; no obstante, el hecho de que las tumbas en sí no difieran del resto de enterramientos contemporáneos, puesto que se depositaron en el interior de cistas de sillería -el masculino incluso formando parte de un grupo de tres sepulturas-, con ajuares en sintonía con la media y sin ningún tipo de superestructura visible al exterior -es decir, sin voluntad expresa de permanecer en la memoria "cívica" de la comunidad- nos inclina a pensar que no se trata de enterramientos "públicos" al estilo del personaje enterrado en la sepultura monumental de la Casa del Obispo, sino de tumbas de una élite comercial enriquecida en Occidente, en una exhibición del posicionamiento económico, y por ende social, adquirido.

En cualquier caso, la presencia excepcional de los sarcófagos sidonios en Gadir no haría sino recalcar la riqueza y dinamismo alcanzados por la antigua fundación tiria durante el s. V a.C., cuya oligarquía gozaría de la capacidad económica y la posición social suficiente para procurarse estos objetos de lujo a través de una red de intercambio elitista a nivel mediterráneo que le permitiría emular, en la lejanía, a la propia monarquía oriental, al menos en el momento de la muerte.

\section{El territorio insular de Gadir como centro sacralizado del poder}

Algunos autores han propuesto que el territorio insular tuviera desde su origen un carácter eminentemente "sagrado", como expresión simbólica de la ciudad (Ruiz Mata 1999, 283, 287 y 311). A esta circunstancia no fueron ajenos los escritores griegos que visitan y describen Gadir, que se hacen eco de la atmósfera religiosa que impregna la ciudad (Philostr. VA, IV, 47 y V, 4; Gener et al. 2014b: 123). De acuerdo con esta idea, mientras que en las islas las actividades predominantes serían las de carácter religioso, el grueso de la población se asentaría en los núcleos urbanos continentales, donde también residiría el poder político/administrativo (Ruiz Mata, Pérez y Gómez 2014: 83), situación que se perpetuaría en el tiempo. A favor de esta hipótesis se podría aducir lo reducido de las dimensiones de la ciudad post-colonial emplazada en Kotinoussa, ubicada, por ende, en un terreno pobre desde el punto de vista productivo $\mathrm{y}$, en contraposición, la relativa riqueza de las evidencias religiosas y cultuales de las islas.
Sin entrar a valorar esta hipótesis, éste sería el momento en que se monumentalizarían los templos tradicionales como muestra el célebre capitel protoeólico relacionado con el Kronion, cuya datación ha sido rebajada recientemente hasta los ss. VI-V a.C. (Marín Ceballos y Jiménez Flores 2011a: 218). Fecha que coincide con la intensificación de los cultos en torno al vecino santuario de Astarté, de cuyo entorno se han recuperado un importante lote de terracotas y otros objetos litúrgicos con una amplia cronología que se inicia en el s. VII a.C. (Maya et al. 2014: 165-167). Testimonio de lo anterior sería la constatación de un taller local de fabricación de terracotas para el culto, fechado inicialmente en el s. V a.C. aunque la opinión generalizada es que la producción debe retrasarse hasta los ss. IV-III a.C. (Marín Ceballos y Belén 2011: 203-204).

A los tres templos clásicos citados por las fuentes (Herakleion, Kronion y santuario de Astarté) se ha sumado en los últimos años la evidencia del complejo cultual subterráneo que se excava junto al enterramiento de la Casa del Obispo (Gener et al. 2014b: 140), donde se desarrolla un culto de tipo ctónico que a partir del s. II a.C. adquiere connotaciones salutíferas (Gener et al. 2014b: 144 y 149), de lo que se ha inferido un posible culto a Asklepios (¿quizás sustituyendo a Eshmun?) (Gener et al. 2014b: 150).

Las acciones cultuales no se reducen a las practicadas en los templos. Son múltiples los vestigios que han llegado a nosotros sobre la existencia de pequeños lugares de culto, normalmente situados a cielo abierto, sin estructuras edilicias destacadas. Sólo a partir de momentos más recientes se documentan pavimentos y muretes que hemos interpretado como altares al aire libre (Niveau de Villedary 2009: 54 y 59).

Entre las evidencias más antiguas podemos situar la actividad ritual desarrollada en torno al enterramiento y complejo cultual de la Casa del Obispo, con presencia de ofrendas de distinta naturaleza destacando la presentación de alimentos cocinados, libaciones y ofertas de incienso y olor (Gener et al. 2014b: 144-146). En otras ocasiones se realizan ofrendas luminosas como en el conjunto recuperado durante las excavaciones de un solar muy cercano al taller de terracotas anteriormente citado, formado por una lucerna de doble mecha colocada sobre un pequeño soporte y acompañada por una urna rellena de arena de playa muy limpia (Niveau de Villedary 2009, 54; fig. 16 y fig. 17). En ambos ejemplos las ofrendas se depositan directamente sobre el estrato de 
arena dunar sin más ceremonias, manifestando la práctica habitual de una piedad popular cuyos testimonios se diseminan por un amplio espacio y que quizás sean el reflejo de la aludida "sacralidad" de la isla.

\section{Recapitulación y síntesis. La reafirmación de la identidad ciudadana de Gadir en Época Clásica y la (cuestionada) hegemonía gadirita}

En definitiva, el nuevo orden generado no es sino la cristalización, como otro autores han señalado (López Castro 2003), de un proceso iniciado en momentos anteriores y que apenas si hemos bosquejado en estas líneas.

Generalmente, la tradición historiográfica ha prestado más atención a los momentos iniciales de la colonización fenicia y a los procesos de interacción e integración entre las comunidades indígenas y las poblaciones orientales. Esto ha provocado que el análisis de las fases posteriores esté aún en un estadio muy inicial, por lo tanto se trata de un primer intento de síntesis de la evolución histórica de la ciudad de Gadir (antes Muñoz 1995-96, desde una óptica estrictamente arqueológica y Frutos y Muñoz 2004) y de la consolidación de lo que se ha venido a llamar el modelo urbano.

En cuanto al papel hegemónico de Gadir al frente del resto de ciudades fenicias occidentales planteado hace un par de décadas por O. Arteaga (1994), hoy no queda tan claro. Dicho modelo teórico se fundamentaba en la suposición de la existencia de una conciencia identitaria común fenicia occidental -basada en el origen tirio de todas ellas y manifestada en la pervivencia del culto a los dioses tutelares de la metrópolis en el territorio colonial (López Castro 2004)- en contraposición a la cartaginesa, y en la supuesta supremacía "moral" de Gadir, que le permitiría ostentar un liderazgo al frente de la Liga Púnico-Gaditana, que hoy se pone en duda (Ferrer 2011: 204).

Por el contrario, se propugna una alianza desigual entre Gadir y Cartago, plasmada en los tratados concluidos con Roma y que desembocaría durante la siguiente centuria en el creciente interés de la potencia centromediterránea por los territorios occidentales, hasta el momento fuera de su ámbito de interés directo. La realidad es que, como en su momento percibieron los propios escritores griegos, el poblamiento se articularía en ciudades-estado (poleis) totalmente independientes, que según las circunstancias concretas pudieron $-\mathrm{O}$ no- unificar sus fuerzas (Ferrer 2011: 205).

En suma, aunque hemos intentado aproximarnos de forma global a la evolución histórica de la ciudad de Gadir en estos momentos de transición entre el agotamiento de la sociedad colonial y el triunfo definitivo del modelo cívico, son muchos los aspectos que han quedado sin tratar o que se han tocado de manera tangencial en este trabajo, entre otros los relativos a las instituciones y formas de gobierno o a las relaciones (cambiantes) con Cartago. Tampoco se ha ahondado en la integración de las poblaciones indígenas, ni de los sucesivos aportes y oleadas migratorias y el origen diverso de éstas (Ferrer y Álvarez 2009: 208), que a la postre conducirían a la formación de una nueva sociedad híbrida, o incluso a la propia manera en que esta realidad se traduce en términos de auto-conciencia étnica y/o identitaria (desde un punto de vista tanto horizontal, como vertical, y de las relaciones de género); en definitiva, nos enfrentamos a toda una serie de líneas de investigación apenas esbozadas que constituyen todo un reto para el futuro.

\section{Nota}

1. Departamento de Historia, Geografía y Filosofía. Facultad de Filosofía y Letras. Universidad de Cádiz. Avda. Gómez Ulla s/n. 11003 - Cádiz (España). E-mail: anamaria.niveau@uca.es. Este trabajo se inscribe en el marco de actuación del Grupo HUM-509 del PAIDI y del Proyecto de Investigación de Excelencia de la Junta de Andalucía "Los inicios de la presencia fenicia en el sur de la Península Ibérica y el Norte de África: Economía, paleoambiente y morfología urbana"(P12-HUM-2674). 


\section{REFERENCIAS BIBLIOGRÁFICAS}

Alarcón Castellanos F. J. (2010): Enterramientos fenicio-púnicos hallados en 1997 en un solar de la C/ Tolosa Latour. Las necrópolis de Cádiz. Apuntes de arqueología gaditana en Homenaje a J.F. Sibón (Niveau de Villedary, A.M. y Gómez Fernández, V., coords.), Servicio de Publicaciones de la Diputación de Cádiz - Servicio de Publicaciones de la Universidad de Cádiz, Cádiz: 93-119.

Almagro-Gorbea, M.; López Rosendo, M.E.; Mederos Martín, A.; Torres Ortiz, M. (2010): Los sarcófagos antropoides de la necrópolis de Cádiz. Mainake, XXXII, I: 357-394.

Alvar Ezquerra, J. (1986): Theron, rex Hispaniae Citerior. Gerión, 4: 161-175.

Álvarez Martí-Aguilar, M. (2006): El origen del ariete: Cartago versus Gadir a fines del s. III a.C. Initia Rerum. Sobre el concepto del origen en el mundo antiguo, Spicum, Málaga: 125-140.

Álvarez Martí-Aguilar, M. (2014): ¿Mentira fenicia? El oráculo de Melqart en los relatos de fundación de Tiro y Gadir. Fraude, mentiras y engaños en el mundo antiguo (Marco Simón, F.; Pina Polo, F. y Remesal Rodríguez, J., eds.), Col.lecció Instrumenta, 45, Universidad de Barcelona, Barcelona: 13-33.

Álvarez Rojas, A. (1992): Sobre la localización del Cádiz fenicio. Boletín del Museo de Cádiz, V: 17-30.

Arévalo, A.; Bernal, D.; Torremocha, A. (2004): Garum y salazones en el Círculo del Estrecho. Catálogo de la Exposición (Algeciras, 2004). Cádiz.

Arteaga Matute, O. (1994): La liga púnico-gaditana. Aproximación a una visión histórica occidental, para su contrastación con el desarrollo de la hegemonía cartaginesa en el mundo Mediterráneo. Cartago, Gadir, Ebusus y la influencia púnica en los territorios hispanos. VIII Jornadas de Arqueología feniciopúnica de Ibiza. Ibiza, 1993, Trabajos del Museo Arqueológico de Ibiza, 33, Ibiza: 23-57.

Aubet Semmler, M.E. (2010): The Phoenician Cemetery of Tyre. Near Eastern Archaeology, 73, 2-3: 144155.

Bechtold, B. (2008): Observations on the amphora repertoire of Middle Punic Carthage. Carthage Studies, 2, Ghent University, Gent.

Blanco Jiménez, F. J. (2010): Memoria Final de la Intervención Arqueológica realizada en: Calle Mirador 12, 14 y 16 / Calle Santo Domingo 25 y 27 (Barrio de Santa María - Cádiz). Memoria Inédita depositada en la Delegación de Cultura de Cádiz, Cádiz.

Bueno Serrano, P.; Cerpa Niño, J. A. (2008): Un nuevo enclave fenicio descubierto en la bahía de Cádiz: El Cerro del Castillo, Chiclana. Spal, 17: 169-206.

Bueno Serrano, P.; García-Menárguez, A.; Prados Martínez, F. (2013): Murallas fenicias de Occidente. Una valoración conjunta de las defensas del Cerro del Castillo (Chiclana, Cádiz) y del Cabezo Pequeño del Estaño (Guardamar, Alicante). Herakleion, 6: 27-75.

Cabrera Bonet, P. (1994): Cádiz y el comercio de productos griegos en Andalucía Occidental durante los siglos V y IV a.C. Trabajos de Prehistoria, 51, nº 2: 89-101.

CABrera Bonet, P. (1998a): El comercio turdetano a través de las cerámicas griegas La colonización fenicia en la Bahía de Cádiz a través del Castillo de Doña Blanca. Puerto de Santa María. (Ruiz Mata, D., ed.). Memoria inédita, Consejería de Cultura, Sevilla: 473-481.

CABrera Bonet, P. (1998b): Las ánforas griegas y el comercio mediterráneo La colonización fenicia en la Bahía de Cádiz a través del Castillo de Doña Blanca. Puerto de Santa María. (Ruiz Mata, D., ed.). Memoria inédita, Consejería de Cultura, Sevilla: 326-372.

Cobos, L.; Muñoz, A.; Perdigones, L. (1995-96): Intervención arqueológica en el solar del antiguo teatro Andalucía de Cádiz: La factoría de salazones y la representación gráfica del Faro de Gades. Boletín del Museo de Cádiz, VII: 115-121.

Córdoba Alonso, I.; D. Ruiz Mata (2005): El asentamiento fenicio arcaico de la calle Cánovas del Casti1 lo (Cádiz). Un análisis preliminar. El Periodo Orientalizante. Actas del III Simposio Internacional de Arqueología de Mérida: Protohistoria del Mediterráneo Occidental (Mérida, 2003) (Celestino Pérez, S. y Jiménez Avila, J., eds.), Anejos de Archivo Español de Arqueología, XXXV, 2, Consejo Superior de Investigaciones Científicas, Mérida: 1269- 1322.

Domínguez Monedero, A. (2012): Gadir. Mito y arqueología en el nacimiento de ciudades legendarias de la Antigüedad (Fornis, C., ed.), Secretariado de Publicaciones, Universidad de Sevilla, Sevilla: 153-197 
Domínguez-Bella, S.; March, R.J.; Gener Basallote, J.M.; Martínez, J. (2011): Análisis de restos orgánicos de la tumba púnica de la Casa del Obispo. Reconstruyendo la memoria fenicia en el Occidente del Mediterráneo. Gadir y el Círculo del Estrecho revisados. Propuestas de la arqueología desde un enfoque social (Domínguez Pérez, J.C., ed. cient.), Servicio de Publicaciones, Universidad de Cádiz, Cádiz: 307-319.

Ferrer Albelda, E. (2010): La necrópolis fenicio-púnica de Gadir. Reflexiones a partir de un discurso identitario no esencialista. Las necrópolis de Cádiz. Apuntes de arqueología gaditana en Homenaje a J.F. Sibón (Niveau de Villedary, A.M. y Gómez Fernández, V., coords.), Servicio de Publicaciones de la Diputación de Cádiz - Servicio de Publicaciones de la Universidad de Cádiz, Cádiz: 69-91.

Ferrer Albelda, E. (2011): Unidad y diversidad de los fenicios en el periodo postcolonial (I): la visión exoétnica. Fenicios en Tartesos: nuevas perspectivas (Álvarez Martí-Aguilar, M., ed.), BAR International Series, 2245, Archaeopress, Oxford: 193-212.

Ferrer Albelda, E.; Álvarez Martí-Aguilar, M. (2009): Comunidad cívica e identidad en la Iberia púnica. Identidades, culturas y territorios en la Andalucía prerromana (Wulff Alonso, F. y Álvarez Martí-Aguilar, M., eds.), Servicio de Publicaciones de la Universidad de Málaga - Secretariado de Publicaciones de la Universidad de Sevilla, Málaga: 205-235.

Frutos Reyes, G. DE; Muñoz Vicente, Á. (2004): La incidencia antrópica del poblamiento fenicio-púnico desde Cádiz a Sancti Petri. Gadir-Gades. Nueva perspectiva interdisciplinar (Chic García, G.; Frutos Reyes, G. de; Muñoz Vicente, Á. y Padilla Monge, A., eds.), Serie Historia, Padilla Libros Editores\&Libreros, Sevilla: 5-69.

García Vargas, E.; Ferrer Albelda, E. (2012): Más allá del banquete: el consumo de las salazones ibéricas en Grecia (siglos V y IV a.C.). Sal, pesca y salazones fenicios en Occidente. XXVI Jornadas de Arqueología fenicio-púnica (Ibiza, 2011). (Costa, B. y Fernández, J.H., ed.), Treballs del Museu Arqueològic d'Eivissa i Formentera, 67, Museu Arqueològic d'Eivissa i Formentera, Eivissa: 85-121.

Gener, J.M.; Navarro, M.Á.; Pajuelo, J.M.; Torres, M.; Domínguez-Bella, S. (2012): Las crétulas del siglo VIII a. C. de las excavaciones del solar del Cine Cómico (Cádiz). Madrider Mitteilungen, 53: 134-186.

Gener, J.M.; Navarro, M.Á.; Pajuelo, J.M.; Torres, M.; LóPez Rosendo, E. (2014a): Arquitectura y urbanismo de la Gadir fenicia: el yacimiento del "Teatro Cómico" de Cádiz. Los Fenicios en la Bahía de Cádiz: Nuevas investigaciones (Botto, M., ed.). Collezione di Studi Fenici, 46, Fabrizio Serra Ed., Roma: 14-50.

Gener J. M.; Jurado, G.; Pajuelo, J. M.; Torres, M. (2014b): El proceso de sacralización del espacio en Gadir: el yacimiento de la Casa del Obispo (Cádiz). Parte I. Los Fenicios en la Bahía de Cádiz: Nuevas investigaciones (Botto, M., ed.), Collezione di Studi Fenici, 46, Fabrizio Serra ed., Roma: 123-155.

Gener J. M.; Jurado, G.; Pajuelo, J. M. (e.p.): El monumento funerario de la Casa del Obispo (Cádiz). Nuevas tendencias de investigación en Arqueología funeraria (Niveau de Villedary, A. M., ed.), Collezione di Studi Fenici, Farbizio Serra ed., Roma.

González de Canales, F.; Leonardo, S.; Llompart, J. (2004): El emporio fenicio precolonial de Huelva, ca. 900-770 a.C. Biblioteca Nueva, Madrid.

González de Canales, F.; Leonardo, S.; Llompart, J. (2006): Las evidencias más antiguas de la presencia fenicia en el sur de la Península. Mainake, XXVIII: 105-128.

Lavado, M. L.; Molina, M.; Cobos, L. M.; Blanco, F.; Sibón, F. J. (2000): El asentamiento antiguo de Cádiz a través de las últimas excavaciones arqueológicas. Actas del IV Congreso Internacional de Estudios Fenicios y Púnicos (Cádiz, 1995), II, Universidad de Cádiz, Cádiz: 869-879.

López Castro, J.L. (1992): Pompeyo Trogo (Justino XLIV, 5, 1-4) y el Imperialismo cartaginés en la Península Ibérica. In memoriam J. Cabrera Infante, Universidad de Granada, Granada: 219-235.

López Castro, J.L. (1997): Los fenicios occidentales y Grecia. Xaipe. Homenaje al profesor Fernando Gascó (Presedo, F.J.; Guinea, P.; Cortés, J.M. y Urías, R., eds.), Scriptorium, Sevilla: 95-105.

López Castro, J.L. (2003): La formación de las ciudades fenicias occidentales. Byrsa. Rivista di arte, cultura e archeologia del Mediterraneo punico, 2: 69-120.

López CASTRO, J.L. (2004): La identidad étnica de los fenicios occidentales. Identidades étnicas - Identidades políticas en el mundo prerromano hispano (Cruz Andreotti, G. y Mora Serrano, B., coords.), Servicio de Publicaciones. Universidad de Málaga, Málaga: 149-167.

López Castro, J.L. (2006): Colonials, merchants and alabaster vases: the western Phoenician aristocracy. Antiquity, 80: 74-88. 
López Castro, J.L. (2012): La influencia fenicia y cartaginesa en la organización del territorio hispano. Romanización, fronteras y etnias en la Roma antigua: el caso hispano (Santos Yanguas, J. y Cruz Andreotti, G., eds.), Revisiones de Historia Antigua, VII, Servicio Editorial de la Universidad del País Vasco, Vitoria-Gasteiz: 113-142.

Marín Ceballos, M.C.; Belén Deamos, M. (2011): De Cartago a Cádiz. Notas de iconografía religiosa. Cultos y ritos de la Gadir fenicia (Marín Ceballos, M.C., coord.), Servicio de Publicaciones, Universidad de Cádiz, Cádiz: 191-206.

Marín Ceballos, M.C.; Jiménez Flores, A.M. (2011a): El Kronion de Gadir: una propuesta de análisis. Cultos y ritos de la Gadir fenicia (Marín Ceballos, M.C., coord.), Servicio de Publicaciones, Universidad de Cádiz, Cádiz: 221-245.

Marín Ceballos, M.C.; Jiménez Flores, A.M. (2011b): El Kronion de Gadir: una propuesta de análisis. Cultos y ritos de la Gadir fenicia (Marín Ceballos, M.C., coord.), Servicio de Publicaciones, Universidad de Cádiz, Cádiz: 221-245.

Maya, R.; Jurado, G.; Gener, J. M.; López Rosendo, E.; Torres, M.; Zamora, J. Á. (2014): Nuevos datos sobre la posible ubicación del Kronion de Gadir: Las evidencias de época fenicia arcaica. Los Fenicios en la Bahía de Cádiz: Nuevas investigaciones (Botto, M., ed.), Collezione di Studi Fenici, 46, Fabrizio Serra ed., Roma: 157-180.

Muñoz Vicente, Á. (1983-84): Aportaciones al estudio de las tumbas de sillería prerromanas de Cádiz. Boletín del Museo de Cádiz, IV: 47-54.

MuÑoz Vicente, Á. (1995-96): Secuencia histórica del asentamiento fenicio-púnico de Cádiz: Un análisis crono-espacial tras quince años de investigación arqueológica. Boletín del Museo de Cádiz, VII: 77-105.

Muñoz Vicente, Á. (1998): Notas sobre la necrópolis fenicia de Cádiz. Homenaje al Profesor Carlos Posac Mon, Instituto de Estudios Ceutíes, I: 131-141.

Niveau de Villedary, A.M. (2006): Banquetes rituales en la necrópolis púnica de Gadir. Gerión, 24, 1: 3564.

Niveau de Villedary, A.M. (2007): Nuevos datos sobre la presencia de "pebeteros en forma de cabeza femenina" en la Bahía de Cádiz. Imagen y culto en la Iberia prerromana: en torno a los llamados "pebeteros en forma de cabeza femenina" (Marín Ceballos, M. C. y Horn, F., eds.), Spal Monografías, IX, Secretariado de Publicaciones de la Universidad de Sevilla, Sevilla: 151-194.

Niveau de Villedary, A.M. (2009): Ofrendas, banquetes y libaciones. El ritual funerario en la necrópolis púnica de Cádiz. Spal Monografías, XII, Secretariado de Publicaciones, Universidad de Sevilla - Servicio de Publicaciones, Universidad de Cádiz, Sevilla.

Niveau de Villedary, A.M. (2014): De colonia a ciudad. Algunos apuntes sobre la situación y naturaleza de la ciudad de Gadir. In amicitia. Miscel-lània d'estudis en homenatge a Jordi H. Fernández (Ferrando Ballester, C. y Costa Ribas, B., eds.), Treballs del Museu Arqueològic d'Eivissa i Formentera, 72, Museu Arqueològic d'Eivissa i Formentera, Eivissa: 485-515.

Padilla Monge, A. (2014): Los inicios de la presencia fenicia en Cádiz. Gerión, 32: 15-56.

Perdigones, L.; Muñoz, A.; Pisano, G. (1990): La necrópolis fenicio-púnica de Cádiz. Siglos VI al IV a.C. Studia Punica, 7, Roma.

Perea, A.; Montero, I.; Cabrera, A.; Feliú, M.J.; Gayo, M.D.; Gener, J.M. ; Pajuelo, J.M. (2004): El ajuar de oro de la tumba fenicia del Obispo. Cádiz. Tecnología del Oro antiguo: Europa y América (Perea, A.; Montero, I. y García-Vuelta, O., eds.), Anejos de Archivo Español de Arqueología, XXXII, CSIC, Madrid: 231-241.

Prados Martínez, F. (2008): Arquitectura púnica: los monumentos funerarios, Anejos de Archivo Español de Arqueología, XLIV, CSIC, Madrid.

Ramírez Delgado, J. R. (1982): Los primitivos núcleos de asentamiento en la ciudad de Cádiz. Ayuntamiento de Cádiz, Cádiz.

Ruiz Mata, D. (1988): El Castillo de Doña Blanca. Yacimiento clave de la protohistoria peninsular. Revista de Arqueología, 85: 36-48.

Ruiz Mata, D. (1999): La fundación de Gadir y el Castillo de Doña Blanca: Contrastación textual y arqueológica. Complutum, 10: 279-317. 
Ruiz Mata, D.; Pérez, C.J. (1989): El Túmulo 1 de la Necrópolis de "Las Cumbres” (Puerto de Santa María, Cádiz). Tartessos. Arqueología protohistórica del Bajo Guadalquivir, Ausa, Sabadell: 287-295.

Ruiz Mata, D.; Pérez, C.J. (1995): El poblado fenicio del Castillo de Doña Blanca (El Puerto de Santa María, Cádiz). Biblioteca de Temas Portuenses, 5, Ayuntamiento de El Puerto de Santa María, El Puerto de Santa María, Cádiz.

Ruiz Mata, D.; Pérez, C. J.; Gómez Fernández, V. (2014): Una nueva zona fenicia de época arcaica en Cádiz: el solar de la "Calle Ancha, n 29". Los Fenicios en la Bahía de Cádiz: Nuevas investigaciones (Botto, M., ed.), Collezione di Studi Fenici, 46, Fabrizio Serra ed., Roma: 83-122.

SÁez Romero, A.M. (2008): La producción cerámica en Gadir en época tardopúnica (siglos -III/-I). British Archaeological Reports International Series, S1812, Oxford.

SÁEz Romero, A.M. (2011): Balance y novedades sobre la pesca y la industria conservera en las ciudades fenicias del "Área del Estrecho". Pescar con Arte. Fenicios y romanos en el origen de los aparejos andaluces. Catálogo de la Exposición (Baelo Claudia, diciembre 2011-julio 2012) (Bernal Casasola, D., ed. cient.), Monografías del Proyecto Sagena, 3, Universidad de Cádiz, Servicio de Publicaciones, Cádiz: 255-297.

SÁez Romero, A.M. (2014): Fish processing and salted-fish trade in the Punic West: new archaeological data and historical evolution. Fish and ships: production et commerce des salsamenta durant l'Antiquité. Actes de l'atelier doctoral (Rome 18-22 juin 2012) (Botte, E. y Leitch, V., eds.), Bibliothèque d'Archéologie Méditerranéenne et Africaine, 17, Centre Camille Jullian, Paris - Aix-en-Provence.

Sáez Romero, A.M.; Belizón Aragón, R. (2014): Excavaciones en la Calle Hércules, 12 de Cádiz. Avance de resultados y primeras propuestas acerca de la posible necrópolis fenicia insular de Gadir. Los Fenicios en la Bahía de Cádiz: Nuevas investigaciones (Botto, M., ed.), Collezione di Studi Fenici, 46, Fabrizio Serra ed., Roma: 181-201.

SÁez Romero, A.M.; Díaz Rodríguez, J.J. (2010): La otra necrópolis de Gadir/Gades. Enterramientos asociados a talleres alfareros en su hinterland insular. Las necrópolis de Cádiz. Apuntes de arqueología gaditana en Homenaje a J.F. Sibón (Niveau de Villedary, A.M. y Gómez Fernández, V., coords.), Servicio de Publicaciones de la Diputación de Cádiz - Servicio de Publicaciones de la Universidad de Cádiz, Cádiz: 251-337.

SÁez Romero, A.M.; Gutiérrez López, J.M.; Reinoso del Río, M.C. (e.p.): Análisis de los materiales procedentes del saladero púnico Puerto-19 (El Puerto de Santa María, Cádiz): una nueva propuesta de datación e interpretación del yacimiento. Anuario Arqueológico de Andalucía, Sevilla.

SÁez Romero, A. M.; Montero Fernández, A. I.; Díaz Rodriguez, J. J. (2005): Nuevos vestigios del santuario gadirita de Melqart en Sancti Petri (San Fernando, Cádiz). El Periodo Orientalizante. Actas del III Simposio Internacional de Arqueología de Mérida: Protohistoria del Mediterráneo Occidental (Mérida, 2003) (Celestino Pérez, S. y Jiménez Avila, J., eds.), Anejos de Archivo Español de Arqueología, XXXV, 2, Consejo Superior de Investigaciones Científicas, Mérida: 873-878.

SÁnCheZ, V.; Galindo, L.; Juzgado, M.; Dumas, M. (2012): El asentamiento fenicio de la Rebanadilla a finales del siglo IX A.C. Diez años de Arqueología Fenicia en la provincia de Málaga (2001-2010) (García Alfonso, E., ed), Consejería de Cultura y Deporte, Málaga: 67-85.

Torres Ortiz, M. (2008): Los “tiempos" de la precolonización. Contacto cultural entre el Mediterráneo y el Atlántico (siglos XII-VIII ane). La precolonización a debate (Celestino, S.; Rafel, N. y Armada, X. L., ed.), Serie Arqueológica, Escuela Española de Historia y Arqueología en Roma. CSIC, 11, Madrid: 59-91.

Torres Ortiz, M. (2010): Sobre la cronología de la necrópolis fenica arcaica de Cádiz. Las necrópolis de Cádiz. Apuntes de arqueología gaditana en Homenaje a J.F. Sibón (Niveau de Villedary, A.M. y Gómez Fernández, V., ed.), Servicio de Publicaciones de la Diputación de Cádiz - Servicio de Publicaciones de la Universidad de Cádiz, Cádiz: 31-67.

Torres, M.; López Rosendo, E.; Gener, J.M.; Navarro, M.A.; Pajuelo, J.M. (2014): El material cerámico de los contextos fenicios del "Teatro Cómico" de Cádiz: un análisis preliminar. Los Fenicios en la Bahía de Cádiz: Nuevas investigaciones (Botto, M., ed.), Collezione di Studi Fenici, 46, Fabrizio Serra ed., Roma: 51-82.

Zamora, J.Á.; Gener, J.M.; Navarro, M.Á.; Pajuelo, J.M.; Torres, M. (2010): Epígrafes fenicios arcaicos en la excavación del Teatro Cómico de Cádiz (2006-2010). Rivista di Studi Fenici, XXXVIII, 2: 203-236. 